\section{CPS-282 EPIDEMIOLOGY AND CLINICAL COURSE OF PATIENTS WITH CANCER DIAGNOSED WITH SARS-COV-2 INFECTION}

${ }^{1} \mathrm{I}$ Taladriz Sender*, ${ }^{2} \mathrm{FJ}$ Garcia Moreno, ${ }^{2} \mathrm{C}$ Villanueva Bueno, ${ }^{1} \mathrm{~J}$ Vicente Valor, ${ }^{1} \mathrm{JL}$ Revuelta Herrero, ${ }^{2} \mathrm{R}$ Collado Borell, ${ }^{2} \mathrm{~V}$ Escudero Vilaplana, ${ }^{2} \mathrm{E}$ Gonzalez-Haba Peña, ${ }^{2} \mathrm{M}$ Sanjurjo Saez. 'Hospital General Universitario Gregorio Marañón, Pharmacy, Madrid, Spain; ${ }^{2}$ Hospital General Universitario Gregorio Marañon, Pharmacy, Madrid, Spain

\subsection{6/ejhpharm-2021-eahpconf.114}

Background and importance Cancer patients are a vulnerable population for SAR-CoV-2 infection.

Aim and objectives The aim of our study was to describe the epidemiology and clinical course of patients with cancer infected with SARS-Cov-2, attending hospital.

Material and methods A retrospective observational study was conducted in cancer patients attending a tertiary hospital for SARS-CoV-2 infection during the period 3 January 2020 to 31 May 2020. Demographic and clinical variables were analysed: comorbidities, tumour diagnosis, tumour stage and whether they had received anticancer treatment in the last month (active treatment). The clinical course was evaluated by hospital admission, pneumonia, oxygen therapy requirements, the development of acute respiratory distress syndrome (ARDS), admission to ICU, mortality rate and mortality rate $<30$ days from admission.

Quantitative variables were expressed as means (SD). The association between dichotomous variables or proportions was compared using Fisher's exact test and between quantitative variables using the Mann-Whitney U test.

Results 112 patients were included, 59.8\% (67) were men, mean age $67 \pm 13.4$ years. $94.6 \%$ (106) were Caucasian $(4.4 \%$ (5) Latino). 61.6\% (69) were non-smokers, $25 \%$ (28) exsmokers and $13.4 \%$ (15) current smokers; $11.6 \%$ (13) had obesity. The most frequent comorbidities were: 57.1\% (64) arterial hypertension, $34.8 \%$ (38) cardiovascular disease, $32.1 \%$ (36) diabetes mellitus and 21.4\% (24) COPD.

The most frequent cancer diagnosis were: $18.8 \%$ (21) breast cancer, $17.9 \%$ (20) lung cancer, 16.1\% (18) colorectal cancer and $12.5 \%$ (14) prostate cancer. Tumour stage: $55.4 \%$ (62) metastatic disease, 25\% (28) localised disease and 19.6\% (22) locally advanced disease. $60.7 \%$ (68) of patients received active cancer treatment (42.7\% chemotherapy, $32.3 \%$ hormonal treatment, $16.2 \%$ targeted therapy, $7 \%$ immunotherapy and $2.9 \%$ radiotherapy). At admission, $85.7 \%$ (96) of patients

\begin{tabular}{|c|c|c|}
\hline & $\begin{array}{l}\text { Cancer patients } \\
(n=112)\end{array}$ & $\begin{array}{l}\text { Cancer patients receiving } \\
\text { anticancer therapy }(n=68)\end{array}$ \\
\hline Hospital admission rate & $92.9 \%(104)$ & $94.1 \%(64)$ \\
\hline Mean days of admission & $16 \pm 17$ & $16 \pm 19$ \\
\hline $\begin{array}{l}\text { Oxygen therapy } \\
\text { requirements }\end{array}$ & $29.8 \%(31)$ & $20.6 \%(14)$ \\
\hline ARDS & $28.9 \%(32)$ & $17.7 \%(12)$ \\
\hline Admission to ICU & $7.7 \%(8)$ & $7.3 \%(5)$ \\
\hline Mortality rate & $27.7 \%(31)$ & $25 \%(17)$ \\
\hline $\begin{array}{l}\text { Mortality rate }<30 \text { days } \\
\text { since admission }\end{array}$ & $77.4 \%(24)$ & $70.6 \%(12)$ \\
\hline Second admission rate & $7.7 \%(8)$ & $5.9 \%(4)$ \\
\hline $\begin{array}{l}\text { Second emergency visits } \\
\text { rate }\end{array}$ & $8.9 \%(10)$ & $8.8 \%(6)$ \\
\hline
\end{tabular}

had pneumonia (78.1\% bilateral), 59.9\% (67) had lymphopenia (lymphocytes $<1000 / \mu \mathrm{L}$ ) and 31.3\% (35) had p02 <90\%. The variables for monitoring the clinical course are shown in table 1.

Conclusion and relevance Mortality rate and mortality rate $<30$ days from admission were high. The clinical course in patients with active anticancer treatment was similar to that of all cancer patients. Larger series of patients are needed to continue studying outcomes of SARS-CoV2 infection in cancer patients.

\section{REFERENCES AND/OR ACKNOWLEDGEMENTS}

Conflict of interest No conflict of interest

\section{CPS-283 ONCOHAEMATOLOGICAL PHARMACEUTICAL CARE CONSULTATION. IS THE INFORMATION ON THE EUROPEAN PUBLIC ASSESSMENT REPORT OF DRUGS ENOUGH?}

${ }^{1} V$ Collados Arroyo* ${ }^{1}$ A Henares López, ${ }^{1} \mathrm{C}$ Herranz Muñoz, ${ }^{1} \mathrm{R}$ Fernandez Caballero, ${ }^{1}$ MP Sanchez Sanchez, ${ }^{2} \mathrm{~A}$ Pascual Martinez, ${ }^{3} \mathrm{C}$ Garzon Hernandez. ${ }^{1}$ Hospital Universitario Infanta Elena, Hospital Pharmacy, Valdemoro, Spain; ${ }^{2}$ Hospital Universitario Infanta Elena, Haematology Department, Valdemoro, Spain; ${ }^{3}$ Hospital Universitario Infanta Elena, Oncology Department, Valdemoro, Spain

\subsection{6/ejhpharm-2021-eahpconf.115}

Background and importance The European Public Assessment Report (EPAR) is a document that summarises the scientifictechnical characteristics of drugs. The information that the EPAR should provide is described in the directive 2004/27/ CE, but sometimes it is not enough to cover all scenarios in patients in the oncohaematological pharmaceutical care consultation.

Aim and objectives To evaluate if the information in the EPAR for oral antineoplastic drugs that are dispensed in the outpatient consultation service (OCS) is enough for the management of these drugs in patients with swallowing problems or with nasogastric tubes.

Material and methods We reviewed the EPAR oral antineoplastics drugs dispensed in the OCS. Additionally, articles were searched on Pubmed using the following requests: 'oral antineoplastic', 'swallowing' and 'feeding tube'. If the searches did not provide enough information, we contacted the laboratories by telephone. All information was compiled in an Excel table to analyse the results.

Results The information in the EPAR about oral administration of 32 cytostatics was reviewed. For 20 drugs, the EPAR indicated that the tablets cannot be crushed, bitten or split, and the whole tablet must be swallowed; for five drugs there was no reference about how to administer it; and for five drugs it specified that there was a possibility of dispersing the tablet and indicated how to do it. The EPAR for two drugs was not found.

We performed a bibliographic search of drugs when we did not have enough information (27). Relevant information was found for 11 but information was very limited for 4 (isolated cases of administration outside of what is specified in the EPAR). Finally, for the drugs that we had no information (12), we requested information from 10 laboratories. For five drugs, no additional information was available. Five laboratories told us that they did not advise this type of procedure 